\title{
Formation of Pores in Iron Ore Sinter*
}

\author{
By Haruo KOKUBU, ,* Takuma KODAMA, ** Hiroshi ITAYA ${ }^{* *}$ \\ and Yukio OGUCHI**
}

\section{Introduction}

It is well known that the cold strength of sinter is greatly influenced by porosity. Despite of the importance of this fact, sufficient research has not been made so far on the mechanism which determines sinter porosity ${ }^{1-3)}$ because of the complexity of sintering process.

In this report the mechanism is discussed focusing mainly on the effects of the properties of ores and their melting ratio during sintering on sinter porosity through sinter pot tests.

\section{Experimental Procedures}

\section{Sinter Pot Tests}

Sinter pot tests were carried out on various ores, moisture contents, and coke ratios.

Chemical composition and particle siee distribution of ores used are shown in Tables 1 and 2 respectively, and the blending conditions of three series of experiments are shown in Table 3.

Moisture and coke ratio were varied in order to get a wide range of void fraction and melting ratio of ores in sinter cake. Sinter pot test procedures are as follows:

1) Mixing of dry raw materials (V-type blender)

2) Moisture addition and granulation (1 $\mathrm{m} \phi$-Eirich mixer)

3) Sinter pot test (Pot size: $300^{\phi} \times 300^{\mathrm{h}} \mathrm{mm}$, Suction rate: $\left.1 \mathrm{Nm}^{3} / \mathrm{min}\right)$.

\section{Measurements of Porosity and Melting Ratio}

Porosity is expressed by the following equation:

$$
P=1-\rho_{a} / \rho_{r}
$$

where, $\quad P$ : Porosity $(-)$

$\rho_{u}, \rho_{r}$ : Apparent and real density $\left(\mathrm{g} / \mathrm{cm}^{3}\right)$.

The real density was measured using a pycnometer (JIS-Z-8807). The apparent density of ores was measured using the mercury method (JIS-M-8715) for $2 \sim 4 \mathrm{~mm}$ ores, and the apparent density of iron ore sinter was estimated by measuring the buoyancy in water on the samples prepared by dipping sinter particles of the size of $15 \sim 20 \mathrm{~mm}$ in a $65^{\circ} \mathrm{C}$ paraffin bath for $2 \sim 3 \mathrm{sec}$

The apparent density of sinter particle is given by Eq. (2).

$$
\rho_{s}=W 1 \cdot \rho_{p} \cdot \rho_{w} /\left(W 1 \cdot \rho_{w}+W 2 \cdot\left(\rho_{p}-\rho_{w}\right)-W 3 \cdot \rho_{p}\right)
$$

where, $W 1$ : Sample weight $(\mathrm{g})$

$W 2$ : Weight of paraffin-coated sample (g)

$W 3$ : Apparent weight of paraffin-coated sample dipped in water $(\mathrm{g})$

$\rho_{s}:$ Apparent density of sample $\left(\mathrm{g} / \mathrm{cm}^{3}\right)$

$\rho_{p}$ : Density of paraffin $\left(\mathrm{g} / \mathrm{cm}^{3}\right)$

$\rho_{w}$ : Density of water $\left(\mathrm{g} / \mathrm{cm}^{3}\right)$.

Melting ratios of sinter were determined by using an image analyzer. ${ }^{4}$ )

Table 1. Chemical compositions of ores used. (\%)

\begin{tabular}{c|ccccccc}
\hline Ore & $\mathrm{CaO}$ & $\mathrm{SiO}_{2}$ & $\mathrm{MgO}$ & $\mathrm{Al}_{2} \mathrm{O}_{3}$ & $\mathrm{T.Fe}$ & $\mathrm{FeO}$ & C.W. \\
\hline $\mathrm{A}$ & 0.04 & 1.91 & 0.05 & 3.07 & 61.5 & 0.74 & 6.2 \\
$\mathrm{~B}$ & 0.06 & 1.19 & 0.04 & 1.50 & 65.5 & 0.39 & 30.0 \\
$\mathrm{G}$ & 0.06 & 4.86 & 0.07 & 2.56 & 62.9 & 0.05 & 2.3 \\
$\mathrm{D}$ & 0.05 & 2.09 & 0.05 & 1.79 & 66.0 & 0.22 & 1.4 \\
$\mathrm{E}$ & 0.05 & 2.98 & 0.02 & 1.03 & 66.5 & 0.11 & 0.4 \\
$\mathrm{~F}$ & 0.03 & 3.01 & 0.03 & 1.14 & 66.2 & 0.40 & 0.6 \\
\hline
\end{tabular}

\begin{tabular}{|c|c|c|c|c|c|c|c|c|}
\hline \multirow{2}{*}{ Ore } & \multicolumn{7}{|c|}{ Particle size $(\mathrm{mm})$} & \multirow{2}{*}{$\begin{array}{c}\mathrm{MS} \\
(\mathrm{mm})\end{array}$} \\
\hline & $4 \sim 2$ & $2 \sim 1$ & $1 \sim 0.5$ & $0.5 \sim 0.25$ & $0.25 \sim 0.125$ & $0.125 \sim 0.062$ & $<0.0612$ & \\
\hline A & 23.6 & 7.9 & 14.3 & 15.0 & 17.7 & 12.2 & 9.4 & 1.04 \\
\hline B & 26.3 & 8.3 & 13.1 & 13.6 & 11.4 & 11.5 & 15.8 & 1.10 \\
\hline C & 31.3 & 14.3 & 10.8 & 12.4 & 12.4 & 11.1 & 7.7 & 1.32 \\
\hline $\mathrm{D}$ & 26.6 & 11.1 & 11.5 & 11.9 & 16.5 & 12.3 & 10.0 & 1.14 \\
\hline $\mathrm{E}$ & 55.1 & 22.6 & 11.1 & 6.5 & 2.1 & 1.1 & 1.5 & 2.11 \\
\hline $\mathrm{F}$ & 4.1 & 1.9 & 3.7 & 15.2 & 37.0 & 22.7 & 10.5 & 0.33 \\
\hline
\end{tabular}

Table 2. Particle size distribution of ores used.

MS : Mean size

* Presented to the 109th ISIJ Meeting, April 1985, S46, at Tokyo Institute of Technology in Tokyo. Manuscript received on August 16, 1985: accepted in the final form on November 1, 1985. (C) 1986 ISIJ

** Mizushima Research Department, Iron \& Steel Research Laboratories, Technical Research Division, Kawasaki Steel Corporation, Kawasaki-dori, Mizushima, Kurashiki 712 
Table 3. Blending conditions for sinter pot tests.

\begin{tabular}{|c|c|c|c|c|}
\hline \multirow{2}{*}{$\begin{array}{l}\text { Sintering test } \\
\text { parameters }\end{array}$} & \multicolumn{4}{|c|}{ Blending conditions } \\
\hline & $\begin{array}{l}\text { Ore } \\
(\%)\end{array}$ & $\begin{array}{l}\text { Ore/Lime } \\
(-)\end{array}$ & $\begin{array}{l}\text { Coke } \\
(\%)\end{array}$ & $\begin{array}{c}\text { Moisture } \\
(\%)\end{array}$ \\
\hline Ore & $\begin{array}{l}\text { Ore-G } \\
57.42 \\
\text { Ore-A } \sim \mathrm{F} \\
24.6\end{array}$ & 5.66 & 3.5 & 6.5 \\
\hline $\begin{array}{l}\text { Moisture } \\
\text { content }\end{array}$ & $\begin{array}{l}\text { Ore-C } \\
\quad 82.02\end{array}$ & 5.66 & 3.5 & $0 \sim 8$ \\
\hline $\begin{array}{l}\text { Coke blending } \\
\text { ratio }\end{array}$ & $\begin{array}{c}\text { Ore-G } \\
\text { Bal. }\end{array}$ & 5.66 & $\begin{array}{l}2.8 \sim \\
4.4\end{array}$ & 6.5 \\
\hline
\end{tabular}

\section{Results and Discussion}

On the investigation of the origin of pores in sinter, the following factors should be taken into consideration: (1) Constitution of raw materials; (2) void fraction of the sinter bed before sintering; (3) shrinkage of the bed by sintering; and (4) collapse of voids in sinter cake by crushing.

The void fraction of sinter bed was calculated using Eq. (3) for any mixture of raw materials.

Equation (3) was derived on the assumption of no water penetration into ore, coke and limestone particles.

$$
\varepsilon_{v}=1-\rho_{b} \cdot\left(\operatorname{Mois} / \rho_{w}+\sum_{i} W_{i} / \rho_{a, i}\right) /(100+\text { Mois })
$$

where, $\quad \varepsilon_{v}:$ Void fraction of sinter bed $(-)$

$\rho_{b}$ : Bulk density of sinter bed on wet base $\left(\mathrm{g} / \mathrm{cm}^{3}\right)$

Mois: Moisture content on dry base (\%)

$W_{i}$ : Blending ratio of material $i$ on dry base $(\%)$

$\rho_{a, i}:$ Apparent density of material $i$ (g/ $\left.\mathrm{cm}^{3}\right)$.

Volume shrinkage of the sinter bed $(S h)$ was approximated by vertical shrinkage and collapse of voids in sinter cake by crushing was estimated by comparing the void fraction of the sinter cake with sinter porosity. The void fraction of sinter cake was calculated by the following equations:

$$
\begin{aligned}
\varepsilon_{a} & =\left(\varepsilon_{b}-S h\right) /(1-S h) \\
\varepsilon_{b} & =\varepsilon_{v}+\varepsilon_{o}+\varepsilon_{b}+\varepsilon_{w} \\
\varepsilon_{o} & =\frac{\rho_{b}}{100+\text { Mois }} \sum_{j}( \\
\varepsilon_{c} & =\frac{\rho_{b} \cdot W_{c}}{\rho_{c} \cdot(100+\text { Mois })} \\
\varepsilon_{w} & =\frac{\rho_{b} \cdot \text { Mois }}{\rho_{w} \cdot(100+\text { Mois })}
\end{aligned}
$$$$
\varepsilon_{o}=\frac{\rho_{b}}{100+\text { Mois }} \sum_{j}\left(\frac{W_{o, j}}{\rho_{o, j}}\left(P_{j}+\frac{C_{w, j}}{100 \cdot \rho_{c w}}\right)\right)
$$

where, $C_{w, j}$ : Combined water content in ore $j(\%)$ $P_{j}$ : Porosity of ore $j(-)$

Sh: Shrinkage of sinter bed (-)

$W_{c}$ : Coke blending ratio on dry base $(\%)$

$W_{o, j}$ : Blending ratio of material $j$ on dry base $(\%)$

$\rho_{c}:$ Apparent density of coke $\left(\mathrm{g} / \mathrm{cm}^{3}\right)$

$\rho_{i}$ : Apparent density of material $i$ (g/ $\mathrm{cm}^{3}$ )

$\rho_{c w}$ : Density of combined water $\left(\mathrm{g} / \mathrm{cm}^{3}\right)$

$\rho_{o, j}:$ Apparent density of ore $j\left(\mathrm{~g} / \mathrm{cm}^{3}\right)$

$\varepsilon_{a}$ : Void fraction of sinter cake $(-)$

$\varepsilon_{b}$ : Estimated void fraction of sinter cake on the assumption of no shrinkage (一).

For the estimation of $\varepsilon_{b}$, the volume of pores originating from pores and combined water in ore $\left(\varepsilon_{0}\right)$, and the volume of voids $\left(\varepsilon_{v}\right)$, moisture $\left(\varepsilon_{w}\right)$ and coke $\left(\varepsilon_{c}\right)$ in sinter bed were taken into account as shown in Eq. (5), and the volume of the residual materials was assumed to be kept constant during sintering.

Figure 1 shows relationships between void fraction of sinter cake $\left(\varepsilon_{a}\right)$ and sinter porosity. In the ore type test, sinter porosity is proportional to void fraction of sinter cake. Considering that the void fractions of sinter beds $\left(\varepsilon_{v}\right)$ are almost the same $(0.4$ $\sim 0.41$ ), as shown in Fig. 2, the positive correlation suggests that the pores originating from pores and combined water in ores do not disappear during the sintering and crushing processes. To clarify the process quantitatively, the relation between pore volume originating from pores and combined water in ores and total pore volume in sinter particles was examined on the assumption that the pores originating from ore are completely preserved in sinter particles. As shown in Fig. 3 the positive correlation between the two with a gradient of nearly 1 indicates that the most of the pores originating from ore remain in sinter particles even after the sintering and crushing processes resulting in higher sinter porosity. This presump tion is supported by the fact that the ores with high porosity after heating increase the pores in sinter matrix,${ }^{5)}$ in other words small pores which are too small to disappear by crushing of sinter cake.

While sinter porosity varies inversely as void fraction of sinter cake in the moisture test (Fig. 1(b)), almost no relation is found in the coke blending ratio test (Fig. 1(c)). This indicates that the void fraction of sinter cake does not determine the sinter porosity when the ores tested are the same.

The relationships between melting ratio and void residual ratio in both cases of the moisture test and the coke blending ratio test are shown in Fig. 4. Void residual ratio $\mathrm{R}$ is defined by Eq. (9) to mean the ratio of pore volume left in sinter particles after crushing to total volume of voids in sinter cake.

$$
R=\left(\left(1-\varepsilon_{u}\right) /\left(\varepsilon_{a}\right) \cdot(P /(1-p))\right.
$$

In both cases the void residual ratio varies inversely as the melting ratio. This indicates that the volume of voids which disappear by crushing of the sinter cake increases with a rise in the melting ratio. The change in the melting ratio with moisture content is considered to be caused by the change in the coke combustion behavior due to the difference of quasiparticle structures. ${ }^{6)}$ Photograph 1 shows the changes 

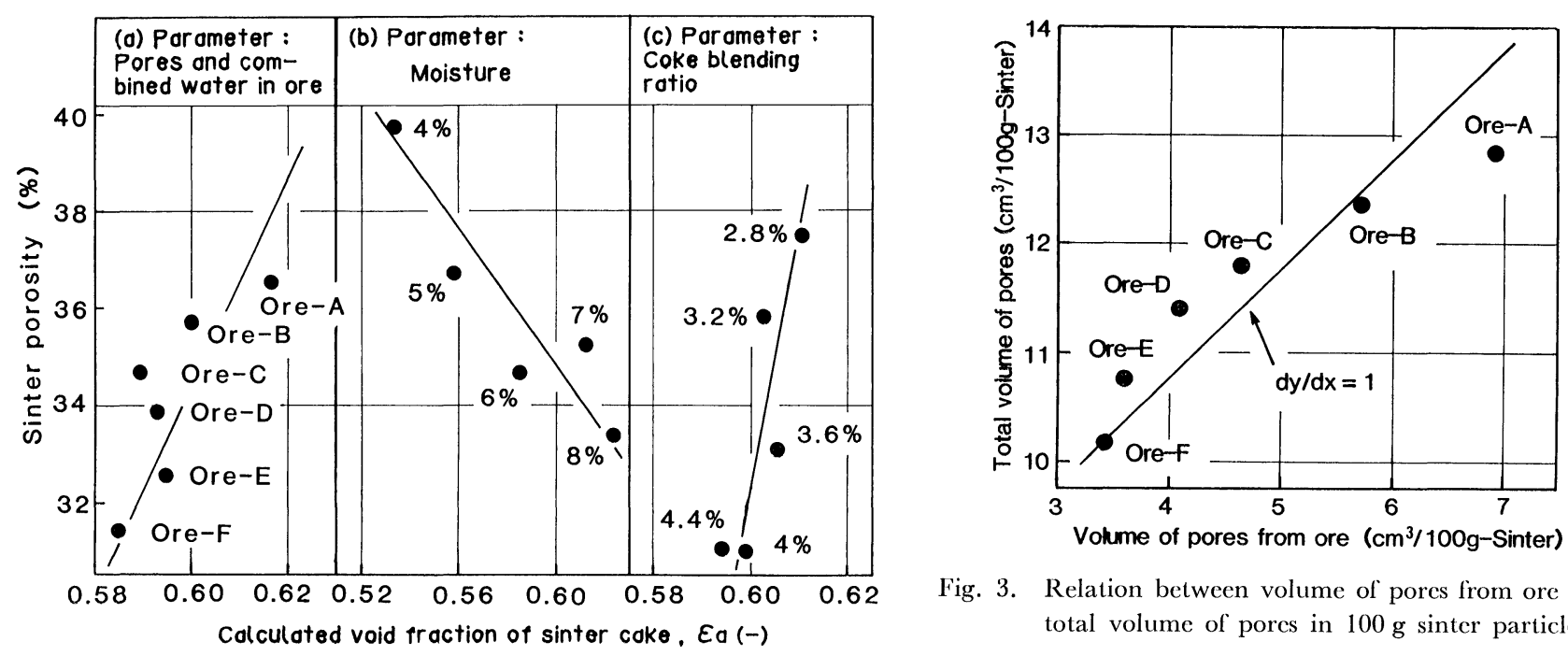

Fig. 3. Relation between volume of pores from ore and total volume of pores in $100 \mathrm{~g}$ sinter particles.

Fig. 1. Relation between calculated void fraction of sinter cake and sinter porosity.
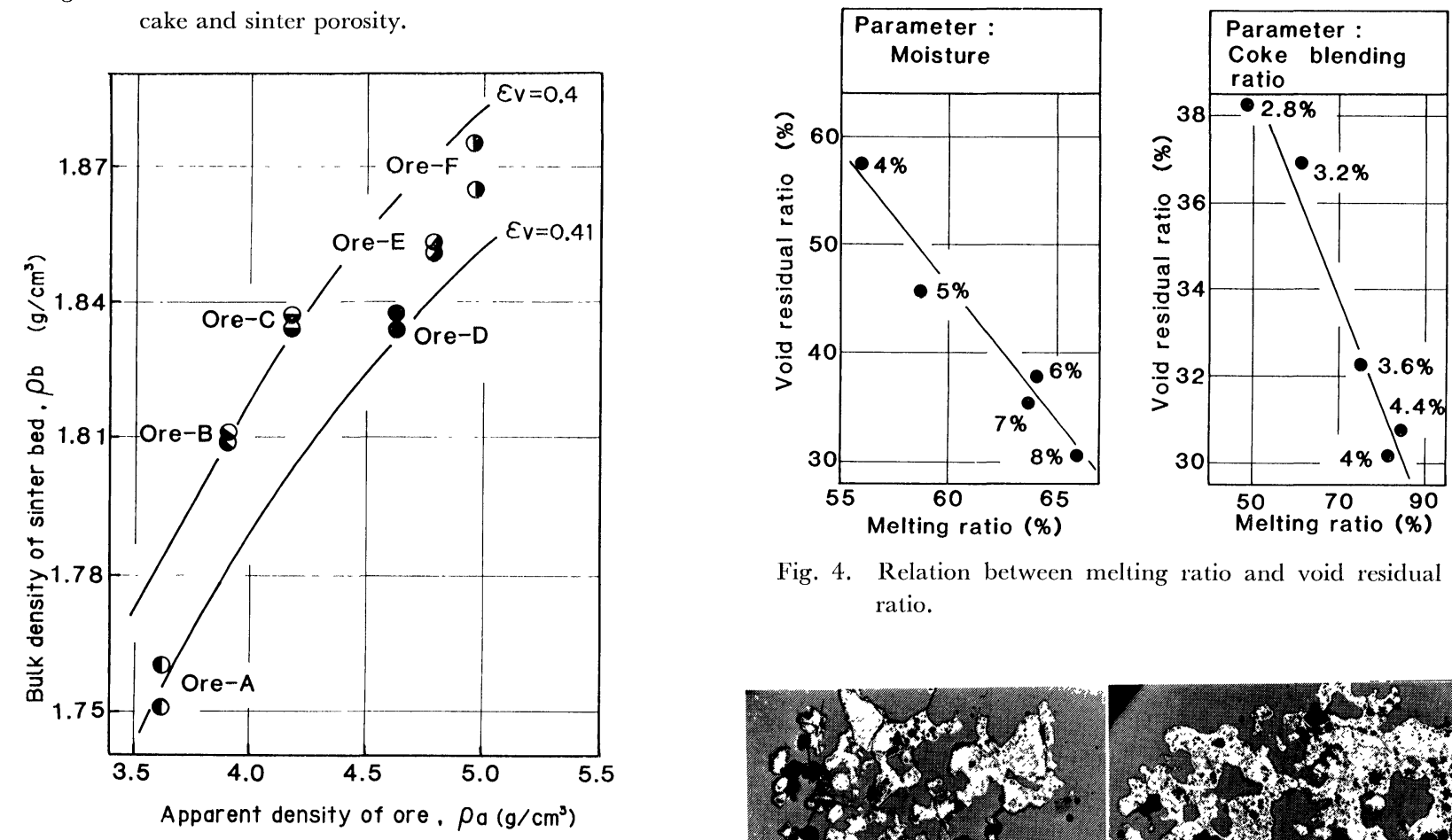

Fig. 4. Relation between melting ratio and void residual ratio.

Fig. 2. Relation between apparent density of ore and bulk density of raw materials in sinter pot.

in sinter macrostructure with melting ratio. Initially dispersed small sinter parts and voids formed at low melting ratio are combined into larger sized ones with increase in melting ratio. This phenomenon was also confirmed indirectly by plant operation data showing a positive correlation between shatter strength and mean diameter of sinter products $5 \mathrm{~mm}$ or greater as shown in Fig. 5. Therefore, the reason the void residual ratio varies inversely as the melting ratio is considered to be initially dispersed small sinter parts and voids formed at low melting ratio being combined into larger sized ones in the sinter cake with increase in melting ratio. Such large voids are preferentially opened and disappear by crushing of the sinter cake resulting in lower sinter porosity and larger sinter products.
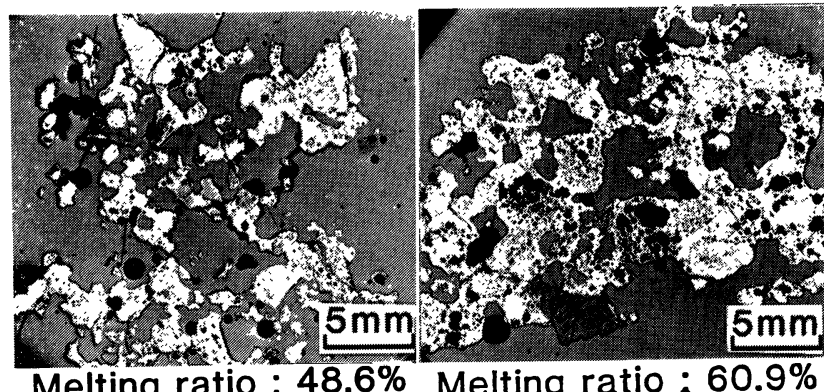

Melting ratio : $48.6 \%$ Melting ratio: $60.9 \%$

Coke : $2.8 \%$

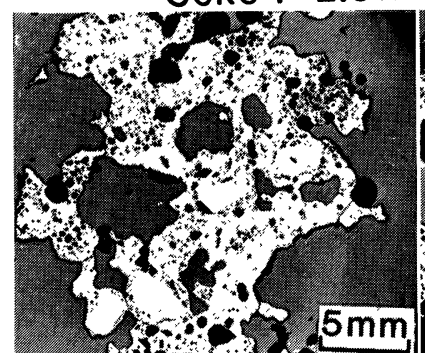

Melting ratio : $75 . \overline{0 \%}$

Coke : $3.6 \%$

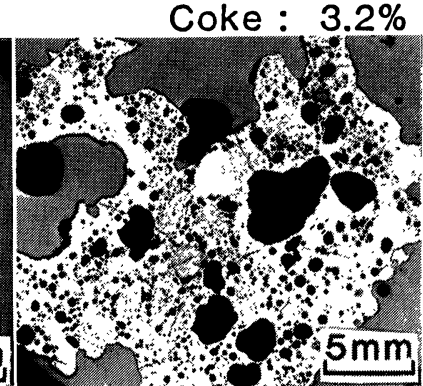

Melting ratio : $81.1 \%$

Coke : $4.0 \%$

Photo. 1. Changes in macrostructure of iron ore sinter with melting ratio. 


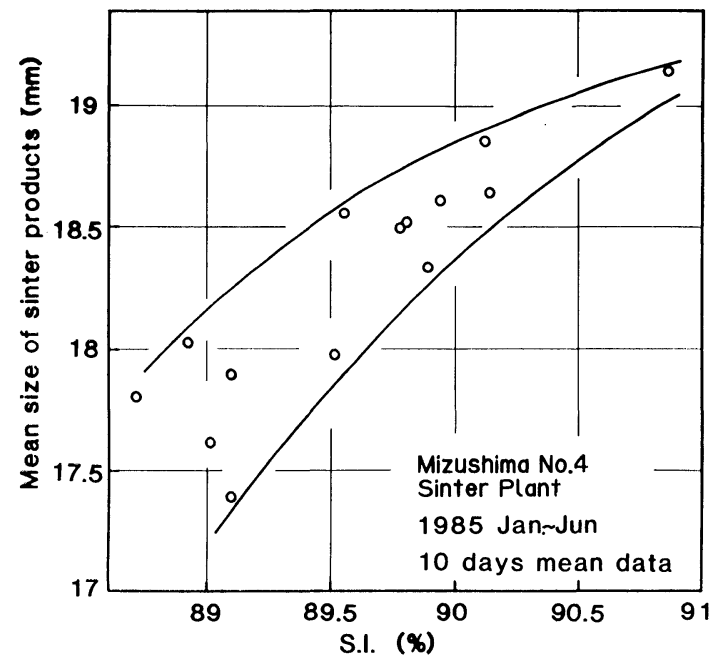

Fig. 5. Relation between shatter strength and mean size of sinter products.

\section{Conclusion}

The origin of pores in sinter was investigated focusing mainly on the effects of pores originating from ore and melting ratio on sinter porosity through sinter pot tests.

(1) The most of the pores originating from pores and combined water in ore are preserved in the sinter even after the sintering and crushing processes resulting in higher sinter porosity.

(2) Initially dispersed small sinter parts and voids formed at low melting ratio combine into larger sized ones in the sinter cake with an increase in melting ratio. Such large voids are preferentially opened and disappear by crushing of the sinter cake resulting in lower sinter porosity and larger sinter products.

\section{REFERENGES}

1) S. Sato, T. Kawaguchi, M. Yoshinaga and M. Ichidate: Telsu-to-Hagané, 68 (1982), S732.

2) E. Kamisaka, H. Sohma and M. Wazima: Tetsu-to-Hagané, 70 (1984), S816.

3) S. C. Panigrahy, M. Jalloui and M. Rigaud: ISS-AIME, 43 (1984), 233.

4) S. Sato, T. Kawaguchi, M. Ichidate and M. Yoshinaga: Tetsu-to-Hagané, 70 (1984), 657.

5) Y. Hida, K. Ito, J. Okazaki, M. Sasaki and Y. Umezu: Tetsu-to-Hagané, 68 (1982) 2166.

6) Y. Hida, M. Sasaki, T. Enokido, T. Iida and S. Uno: Tetsu-to-Hagané, 68 (1982), 400. 